\title{
Sociodemographic profile and social support for post-stroke depression in Kinshasa: A rehabilitation based cross-sectional study
}

\author{
Magloire Nkosi Mpembi ${ }^{1,2^{*}}$, Samuel Mampunza ma Miezi ${ }^{2}$, André Peeters ${ }^{3}$, Marie-Pierre de Partz ${ }^{3}$, \\ Sévérine Henrard ${ }^{1}$, Victoria Kubuta Massamba ${ }^{4}$, Roland Nengi Nsam ${ }^{2}$, Thierry Matonda ma Nzuzi ${ }^{1,2}$, \\ Jean Macq ${ }^{1}$, Vincent Dubois ${ }^{1}$, Eric Constant ${ }^{1}$

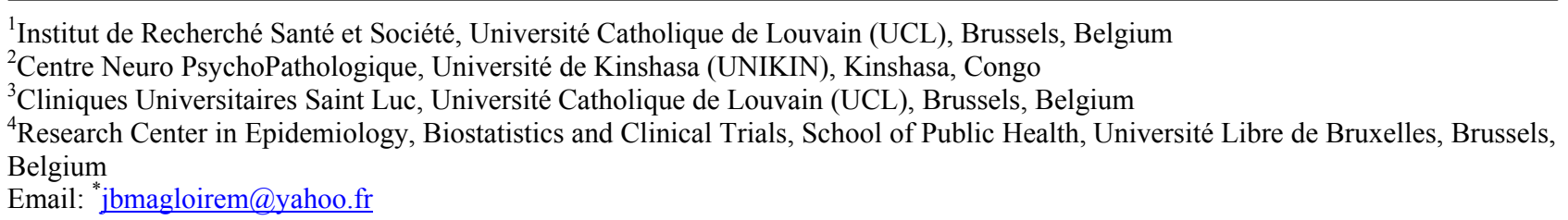

Received 16 June 2013; revised 16 July 2013; accepted 24 July 2013

Copyright (C) 2013 Magloire Nkosi Mpembi et al. This is an open access article distributed under the Creative Commons Attribution License, which permits unrestricted use, distribution, and reproduction in any medium, provided the original work is properly cited.

\begin{abstract}
The World Health Organization has highlighted the emergence of non-communicable chronic diseases, including stroke, in developing countries. As a cause of death, stroke ranks first in Africa. Stroke is the foremost cause of neuropsychiatric disease, including post-stroke depression (PSD) which is a very common disease. Surveys of this condition in Congolese patients are virtually non-existent. The objectives of this study were to assess the prevalence of PSD in Congolese patients and identify associated sociodemographic factors. Age, sex, address, province of origin, social and professional status, education, religion and consumption habits were chosen as indicators or parameters of interest to be examined in this study. The results of descriptive analyses are presented as frequencies for categorical variables and as mean \pm standard deviation for quantitative variables. The association between different variables was assessed using tables of comparisons of proportions and the Chi-square test. Logistic regression was performed to predict the occurrence of PSD. There were more male than female patients. The mean age was $54.67 \pm 12.51$ years. Nearly 3 fourths of the patients were aged less than 65 . The family was the primary source of social support. The majority was satisfied by the social support received from the family. Just over half the study patients $(\mathbf{5 3 . 6 \%})$ had mild to severe depression as assessed by the PHQ9. Univariate analysis and logistic regression indicated a statistically significant

"Corresponding author.
\end{abstract}

association between low educational level and the occurrence of PSD. However, there was no relationship between age, sex or drinking habits and the onset of PSD. The majority of the subjects were satisfied by the social support from their families. Depression was common after stroke with the occurrence of $53.6 \%$. These results highlight the need to investigate, diagnose and treat PSD, which is a risk factor for morbidity and mortality after stroke.

Keywords: Stroke; Post-Stroke Depression; Kinshasa

\section{INTRODUCTION}

The World Health Organization (WHO) defines stroke as the rapid development of clinical signs of local or global cerebral dysfunction with symptoms lasting at least 24 hours or leading to death with no apparent cause other than the vascular origin [1]. There are two types of stroke, depending on the etiology: hemorrhagic stroke and ischemic stroke. Stroke now constitutes a public health problem throughout the world and is the second cause of death worldwide [2]. In the Western countries, stroke is the third largest cause of death after cancer and myocardial infarction [3,4] and remains the leading cause of dependency [4]. Africa is currently experiencing an epidemiological transition. The World Health Organization has highlighted the emergence of non-communicable chronic diseases, including stroke, in developing countries [5]. As a cause of death, stroke ranks first in Africa, above infectious diseases [2]. Eighty-seven percent of 
stroke deaths worldwide occur in developing countries [2]. In addition to the dependency of survivors on others, stroke is the foremost cause of neuropsychiatric disease, including post-stroke depression (PSD) [6-8]. The subject of many publications in Europe and the United States over the last few decades, to our knowledge PSD has not yet been explored in Congolese patients. This study was conducted to fill this gap.

The main objective of this work was to contribute to the epidemiological study of PSD. To achieve this general aim, the following specific objectives were set to assess the prevalence and to determine sociodemographic factors associated with the occurrence of PSD.

\section{METHOD}

\subsection{Study Design and Population}

This was a cross-sectional study involving 58 patients followed for post-stroke hemiplegia at the Centre de rehabilitation pour personnes handicapées de Kinshasa (CRPHK) between August 1 and 31, 2011. Patients with at least three months between the onset of their stroke and the date of the study were included. Exclusion criteria were: lack of consent; confusion or profoundly disturbed conscious state; and inability to understand and execute orders.

\subsection{Description of Measures}

Each patient underwent clinical, neurological and psychiatric examinations. The clinical history was also recorded. A diagnosis of depression was made in 56 of the 58 patients using the Patient Health Questionnaire PHQ9 [9]. Because of marked expressive aphasia, two patients were assessed using the stroke aphasic depression questionnaire SADQ [10]. Age, sex, address, province of origin, social and professional status, educational level, religion as well as alcohol and tobacco consumption were chosen as indicators or parameters of interest to be examined in this study.

\subsection{Statistical Analysis}

Data were analyzed using Epi Info 6.04 software and Stata/IC 11.2. The results of descriptive analyses are presented as frequencies for categorical variables and as mean \pm standard deviation for quantitative variables even for non-normally distributed variables for comparison with other published studies. The statistical significance level adopted was 5\%. Logistic regression was performed to identify predictors of the occurrence of PSD. Due to the sample size, two variables which were significant in univariate analysis $(p<0.05)$ were introduced into the multivariate model. The adequacy of the model was evaluated by Hosmer and Lemeshow test. Outliers were detected by the graph of standardized residuals based on the predicted values. The absence of collinearity was checked by the variance inflation factors.

\section{RESULTS}

The sociodemographic characteristics are shown in Table 1. There were more male than female patients $(\mathrm{n}=$ $37 / 58,63.8 \%$ versus $n=21 / 58,36.2 \%$ ) in our cohort. The mean age was $54.7 \pm 12.5$ years, ranging from 23 to 75 years. Three quarters of patients $(74.1 \%)$ were aged under 65.

Patients from the District of Lukunga, in which is situated the CHPRK, represented $41.4 \%$ of all patients (Figure 1) followed by those from the District of Funa.

The provinces of Bas-Congo and Bandundu were most represented with, respectively, $32.8 \%$ and $25.9 \%$ of pa-

Table 1. Sociodemographic characteristics.

\begin{tabular}{|c|c|c|}
\hline Sociodemographic characteristics & $\mathbf{N}$ & $\%$ \\
\hline \multicolumn{3}{|l|}{ Sex } \\
\hline Men & 37 & $63.80 \%$ \\
\hline Women & 21 & $36.20 \%$ \\
\hline \multicolumn{3}{|l|}{ Age } \\
\hline $15-24$ & 1 & $15-24$ \\
\hline $25-34$ & 5 & $25-34$ \\
\hline $35-44$ & 4 & $35-44$ \\
\hline $45-54$ & 18 & $45-54$ \\
\hline $55-64$ & 15 & $55-64$ \\
\hline $65-74$ & 15 & $65-74$ \\
\hline \multicolumn{3}{|l|}{ Level of education } \\
\hline Without diploma & 8 & $13.80 \%$ \\
\hline Primary & 19 & $32.80 \%$ \\
\hline Secondary & 15 & $25.90 \%$ \\
\hline Graduate & 6 & $10.30 \%$ \\
\hline Master or more & 10 & $17.20 \%$ \\
\hline \multicolumn{3}{|l|}{ Religion } \\
\hline Catholic & 28 & $48.30 \%$ \\
\hline Protestant & 7 & $12.10 \%$ \\
\hline Kimbanguist & 2 & $3.40 \%$ \\
\hline Muslim & 1 & $1.70 \%$ \\
\hline Revivalist & 14 & $24.10 \%$ \\
\hline Other & 6 & $10.30 \%$ \\
\hline \multicolumn{3}{|l|}{ Alcohol } \\
\hline Yes & 46 & $79.30 \%$ \\
\hline No & 12 & $20.70 \%$ \\
\hline \multicolumn{3}{|l|}{ Tobacco } \\
\hline Yes & 15 & $25.90 \%$ \\
\hline No & 43 & $74.10 \%$ \\
\hline
\end{tabular}




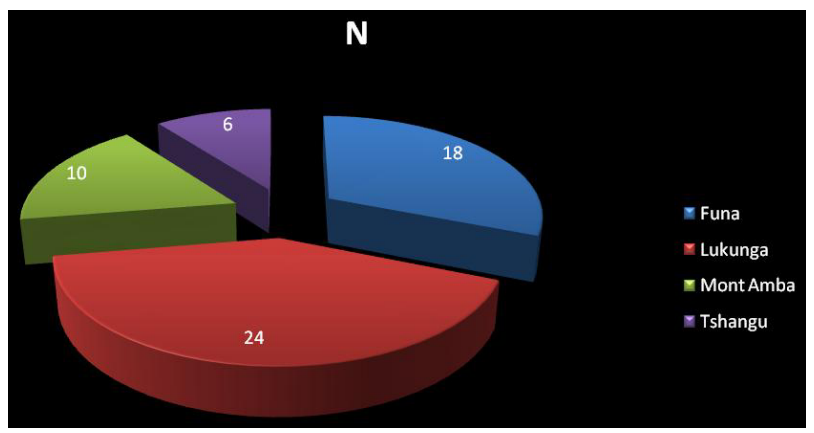

Figure 1. Distribution of patients according the addresses.

Table 2. Distribution of patients according to province of origin.

\begin{tabular}{ccc}
\hline Province & $\mathbf{N}$ & $\mathbf{\%}$ \\
\hline Bas-Congo & 19 & $32.80 \%$ \\
Bandundu & 15 & $25.90 \%$ \\
Kasai oriental & 8 & $13.80 \%$ \\
Equateur & 5 & $8.60 \%$ \\
Kasai occidental & 3 & $5.20 \%$ \\
Angola & 2 & $3.40 \%$ \\
Sud Kivu & 2 & $3.40 \%$ \\
Mali & 1 & $1.70 \%$ \\
Maniema & 1 & $1.70 \%$ \\
Nord Kivu & 1 & $1.70 \%$ \\
Prov orientale & 1 & $1.70 \%$ \\
\hline
\end{tabular}

tients (Table 2).

Patients with an income represented $58.6 \%(n=34 / 58)$ of the study cohort and no income patients represented $41.4 \%$. Nineteen of the patients $(32.8 \%)$ had a primary school certificate and $15(25.9 \%)$ had a high school diploma. Thirty-eight patients (65.5\%) were members of traditional churches (Catholic, Protestant, Kimbanguism, Muslims). Forty-six patients (69\%) reported using alcohol and $15(25.9 \%)$ tobacco. Table 3 shows the social support received by the patients after their episode of stroke and reported by them. The family was the primary source of social support for the study subjects. The majority of the patients were satisfied by the social support received from the family, in the 4 types of social support, including listen and comfort, material support, advices, information and suggestions, and self-confidence recovery support. Just over half the study patients (53.6\%) had mild to severe depression as assessed by the PHQ9.

Table 4 summarizes the relationship between demographic characteristics and PSD as evaluated by the PHQ9 (we defined PSD patients who were identified to have mild to severe depression).

For the subgroup of patients with moderate to severe depression $(n=12)$, there was a statistically significant relationship between PSD, age $\geq 65$ years $(p=0.034)$ and low educational level $(\mathrm{p}=0.02)$.
Table 5 shows the model built by logistic regression and adjusted for age $(\mathrm{n}=56)$. Patients with a high educational level had a low likelihood of developing depresssion (OR [95\% CI]: 0.21 [0.05; 0.92]).

\section{DISCUSSION}

This study assessed the frequency of PSD in a group of Congolese patients and identified sociodemographic factors associated with its occurrence. Twenty-one $(36.2 \%)$ of the 58 patients included in the study were female. The relative overrepresentation of men is in agreement with other data in the literature: women are generally less affected by cardiovascular diseases, such as stroke or myocardial infarction [11-13]. Before the menopause, hormonal factors (estrogen) seem to have a protective effect on cardiovascular diseases female patients [14-16]. The occurrence of PSD observed in this study more than three months after stroke was $53.6 \%$. This rate is similar to the findings of the literature [17]. PSD was present in $66.7 \%$ of female patients compared to $45.7 \%$ of men but the difference between the groups was not statistically significant. Many studies have highlighted the vulnerability of females compared to men for development of PSD [18-25]. It is possible that the lack of a significant difference between men and women observed in this study was due to the relatively small sample size. The average age was $54.7 \pm 12.5$ years, which is relatively low compared to other published data from around the world [23-29]. However, this average age is within the range of observations made in Africa [2]. The incidence of stroke doubles after 65 years [30], but in this study, nearly 3 of 4 patients (74.1\%) were aged less than 65 . This observation can be explained by the low life expectancy of the population of Kinshasa and poor control of risk factors. In the group of patients aged 65 and older, $71.4 \%$ were depressed compared to $47.6 \%$ of the remaining patients $(p=0.12)$. Although PSD tends to increase with age [4], conflicting results have been reported in the literature [30]. This relative overrepresentation of depression in older persons after stroke is one of the arguments used to support the hypothesis of a vascular etiology of depressive disease. Indeed, neuroimaging of older depressed patients often shows signs of clinically undetected strokes [31]. Just over three in five patients $(61.33 \%)$ had achieved at least their secondary school diploma. These patients, therefore, had a higher educational level compared to the general population of DR Congo where the literacy rate is generally low [32]. More patients with a low educational level were depressed $(72 \%)$ than were patients with a higher educational level $(38.7 \%)(p=0.013)$, in contrast to what is observed in the literature where patients with a higher level of education are usually more likely to be depressed [33]. However, some studies have reported similar results to our results [23]. In the logistic regression model, 
Table 3. Social support received by patients after stroke.

\begin{tabular}{|c|c|c|c|c|c|}
\hline \multirow[t]{2}{*}{ Social support } & \multicolumn{4}{|c|}{ Numbers of people } & \multirow[t]{2}{*}{ Satisfaction rate } \\
\hline & 0 & 1 & $2-5$ & $>5$ & \\
\hline \multicolumn{6}{|l|}{ Listen and comfort } \\
\hline Family & $62.10 \%$ & $19.00 \%$ & $13.80 \%$ & $5.20 \%$ & $77.60 \%$ \\
\hline Friends & $77.60 \%$ & $6.90 \%$ & $13.80 \%$ & $1.70 \%$ & $46.60 \%$ \\
\hline Colleagues & $82.80 \%$ & $6.90 \%$ & $6.90 \%$ & $3.40 \%$ & $27.60 \%$ \\
\hline Health professionals & $74.10 \%$ & $10.30 \%$ & $15.50 \%$ & $0.00 \%$ & $48.30 \%$ \\
\hline \multicolumn{6}{|l|}{ Material support } \\
\hline Family & $58.60 \%$ & $15.50 \%$ & $24.10 \%$ & $1.70 \%$ & $60.30 \%$ \\
\hline Friends & $75.90 \%$ & $10.30 \%$ & $10.30 \%$ & $3.40 \%$ & $34.50 \%$ \\
\hline Colleagues & $82.80 \%$ & $6.90 \%$ & $6.90 \%$ & $3.40 \%$ & $22.40 \%$ \\
\hline Health professionals & $96.60 \%$ & $3.40 \%$ & $0.00 \%$ & $0.00 \%$ & $3.40 \%$ \\
\hline \multicolumn{6}{|c|}{ Advice, information and suggestions } \\
\hline Family & $70.70 \%$ & $12.10 \%$ & $15.50 \%$ & $1.70 \%$ & $69.00 \%$ \\
\hline Friends & $72.40 \%$ & $5.20 \%$ & $20.70 \%$ & $1.70 \%$ & $53.40 \%$ \\
\hline Colleagues & $86.20 \%$ & $6.90 \%$ & $5.20 \%$ & $1.70 \%$ & $20.70 \%$ \\
\hline Health professionals & $70.70 \%$ & $10.30 \%$ & $19.00 \%$ & $0.00 \%$ & $37.90 \%$ \\
\hline \multicolumn{6}{|l|}{ Self confidence } \\
\hline Family & $67.20 \%$ & $12.10 \%$ & $17.20 \%$ & $3.40 \%$ & $72.40 \%$ \\
\hline Friends & $79.30 \%$ & $8.60 \%$ & $12.10 \%$ & $0.00 \%$ & $53.40 \%$ \\
\hline Colleagues & $86.20 \%$ & $6.90 \%$ & $6.90 \%$ & $0.00 \%$ & $27.60 \%$ \\
\hline Health professionals & $75.90 \%$ & $10.30 \%$ & $12.10 \%$ & $1.70 \%$ & $37.90 \%$ \\
\hline
\end{tabular}

after adjustment for age, gender, religion, smoking and alcohol, satisfaction of social support in terms of listening, comforting and confidence, patients with a low level of education were more likely to have PSD. Several recent studies have linked low level of education and PSD $[34,35]$. The work of Jopson et al. could partly explain these observations [36]. Studying patients' beliefs about disease shows that there may be a significant gap between the patient's understanding of their illness and the objective health status perceived by the physician. The larger this gap is, the more room it leaves for interpretations that may be detrimental both for the psychological impact of illness (anxiety, depression) and in terms of health-related behavior (medication compliance, lifestyle, etc.). Stroke is a disease that can occur suddenly without any prodrome, forcing patients and family members to rapidly develop coping strategies, here in an environment poor in resources. Patients of limited education, who are often the poorest, seem more vulnerable. The distribution of patients according to religion was similar to that observed in the general population of DR Congo [37]. Religion did not seem to be a discriminatory factor for PSD. Recent publications have highlighted the positive role of faith in the clinical evolution of psychiatric disease in patients after stroke. Giaquinto et al. reported that the strength of religious beliefs was a protective factor against emotional distress after stroke [38]. Researchers are increasingly interested in the role of religion on patient well-being [39-42]; for PSD specifically, further studies on a larger scale are needed to assess the impact of religion on patient evolution [41]. Nearly $80 \%$ of patients reported using alcohol. Alcohol use did not seem to play a significant role in the occurrence of PSD, as reported by many other groups [28,43]. A 1997 article noted, however, a link between alcohol consumption and PSD among male patients [44]. Moreover, excessive alcohol consumption is a risk factor for stroke [45]. In addition, several studies have reported a link between alcohol consumption and vascular depression [46]. Nearly one in four patients said they smoked, but this history was not significantly associated with the occurrence of PSD. Tobacco remains a risk factor for stroke, but does not appear to be associated with PSD $[46,47]$. Fifty-six percent of patients without income and 51.5\% of patients with income were depressed. This difference was not statistically significant, in contrast to what has been reported in the literature. Psychosocial difficulties are generally considered as a risk factor for onset of PSD [48]. More than half the patients reported no social support for all categories. Although the family is not always the primary source of social support, it is perceived as by far the most satisfactory. This result stresses the impor- 
Table 4. Relationships between sociodemographic parameters, social support and PSD.

\begin{tabular}{|c|c|c|c|}
\hline \multirow[t]{2}{*}{$\begin{array}{l}\text { Sociodemographic } \\
\text { characteristics }\end{array}$} & \multicolumn{2}{|c|}{$\begin{array}{c}\text { Mild to severe } \\
\text { depression (PHQ9) }\end{array}$} & \multirow[t]{2}{*}{$\mathbf{P}$} \\
\hline & Yes & No & \\
\hline Sex & & & 0.12 \\
\hline Men & $54.30 \%$ & $45.70 \%$ & \\
\hline Women & $33.30 \%$ & $66.70 \%$ & \\
\hline Age & & & 0.12 \\
\hline$<65$ years & $52.40 \%$ & $47.60 \%$ & \\
\hline$\geq 65$ years & $28.60 \%$ & $71.40 \%$ & \\
\hline Level of education & & & 0.013 \\
\hline Primary or less & $28.00 \%$ & $72.00 \%$ & \\
\hline Secondary or more & $61.33 \%$ & $38.70 \%$ & \\
\hline Occupational status & & & 0.71 \\
\hline Earning & $48.5 \%$ & $51.5 \%$ & \\
\hline No income & $43.5 \%$ & $56.5 \%$ & \\
\hline Religion & & & 0.64 \\
\hline Traditional & $48.60 \%$ & $51.40 \%$ & \\
\hline Revivalist or other & $42.10 \%$ & $57.90 \%$ & \\
\hline Alcohol & & & 0.71 \\
\hline yes & $47.70 \%$ & $52.30 \%$ & \\
\hline No & $41.70 \%$ & $58.30 \%$ & \\
\hline Tobacco & & & 0.75 \\
\hline Yes & $42.90 \%$ & $57.10 \%$ & \\
\hline No & $46.40 \%$ & $52.40 \%$ & \\
\hline \multicolumn{4}{|l|}{ Social support } \\
\hline Listeaning and Reassurance & & & 0.06 \\
\hline Satisfied & $58.30 \%$ & $41.70 \%$ & \\
\hline Not satisfied & $84.10 \%$ & $15.90 \%$ & \\
\hline Confidence & & & 0.009 \\
\hline Satisfied & $41.70 \%$ & $58.30 \%$ & \\
\hline Not satisfied & $81.80 \%$ & $18.20 \%$ & \\
\hline
\end{tabular}

Table 5. Logistic regression of depression.

\begin{tabular}{ccc}
\hline Variables & OR (IC 95\%) & P \\
\hline Level of education & & 0.038 \\
Low educational level & 5.55 & \\
High educational level & 1 & \\
\hline
\end{tabular}

tant role played by the family in Africa, where resources are limited, in assisting patients. The family seems to be the best source of social support to provide relief for the psychological consequences of stroke. In this study, patients who were satisfied with the social support they received particularly related to "listening and comforting" and "restoring confidence" aspects were less likely to be depressed than patients who were not satisfied.
Similar observations highlighting the role of social support in the development of PSD have been reported in several publications. Already in 1991, Morris et al. reported that poor social support was associated with the occurrence and severity of PSD in hospitalized patients [49]. Hilari et al. noted that poor social support and dissatisfaction with the social network were predictors of the development of psychological distress [50]. BodenAlbala et al. reported social isolation as one of the predictors of medical events, such as myocardial infarction, recurrence of stroke, or death post-stroke [51]. According to Farner et al., a low level of social activity before stroke was also associated with the occurrence of PSD 13 months after stroke onset [52].

\section{CONCLUSION}

Depression is a common psychiatric disorder after stroke. The occurrence of PSD observed in this study more than three months after stroke was $53.6 \%$. Of the sociodemographic factors studied, univariate analysis and logistic regression showed a statistically significant association between low education level and the occurrence of PSD. Dissatisfaction with social support in the "restoration of confidence" field was also identified as a risk factor for occurrence of PSD. These results highlight the need to investigate, diagnose and treat PSD, which is a risk factor for morbidity and mortality of patients after stroke.

\section{ACKNOWLEDGEMENTS}

We thank the physiotherapists of CRPHK for support and providing access to the participants.

\section{REFERENCES}

[1] Heller, R.F., Langhorne, P. and James, E. (2000) Improving the Stroke Outcome: the Benefits of Increasing Availability of Technology. Bull World Health Organ, 78, 1338-1343.

[2] Sagui, E. (2007) Les accidents vasculaires cérébraux en Afrique subsaharienne. Médecine Tropicale, 67, 596-600.

[3] Mckay, J. and Mensa, G.A. (2004) The Atlas of heart disease and stroke. WHO-CDC, Geneva.

[4] Grosjean, M. and Courbin C. (2003) Points essentiels du guideline sur la prise en charge des patients souffrant d' accident vasculaire cérébral. Louvain Médical, 122, 575581.

[5] Longo-Mbenza, B., Tonduangu, K., Muyeno, K., Phanzu, M., Kebolo Baku, A., Muvova, D., Lelo, T., Odio, W., Lukoki, L., Bikangi Nkiabungu, F., Kilembe, M., Tshiamala, P., Katalay, L., Mwema, M and Muyembe, T. (2000) Predictors of stroke-associated mortality in Africans. Revue d'Epidémiologie et de Santé Publique, 48, 31-39.

[6] Schmid, A.A., Kroenke, K., Hendrie, H.C., Bakas, T., Sutherland, J.M. and Williams, L.S. (2011) Poststroke depression and treatment effects on functional outcomes. 
Neurology, 11, 1000-1005. doi:10.1212/WNL.0b013e318210435e

[7] Lenzi, G.L., Altieri, M. and Maestrini, I. (2008) Poststroke depression. Revue Neurologique, 164, 837-840. doi:10.1016/i.neurol.2008.07.010

[8] Gabaldón, L., Fuentes, B., Frank-García, A. and DíezTejedor, E. (2007) Poststroke depression: Importance of its Detection and treatment. Cerebrovascular Diseases, 24, 181-188. doi:10.1159/000107394

[9] Carballeira, Y., Dumont, P., Borgacci, S., Rentsch, D., de Tonnac, N., Archinard, M. and Andreoli, A. (2007) Criterion validity of the French version of Patient Health Questionnaire (PHQ) in a hospital department of internal medicine. Psychology and Psychotherapy, 80, 69-77. doi:10.1348/147608306X103641

[10] Sutcliffe, L.M. and Lincoln, N.B. (1998) The assessment of depression in aphasic stroke patients: The development of the stroke aphasic depression questionnaire. Clinical Rehabilitation, 12, 506-513. doi:10.1191/026921598672167702

[11] Thorvaldsen, P., Kuulasma, K., Rajakanga, A.M., Rastenyte, D., Sarti, C. and Wilhelmsen, L. (1997) Stroke trends in WHO MONICA project. Stroke, 28, 5-6. doi:10.1161/01.str.28.3.500

[12] Petrea, R.E., Beiser, A.S., Seshadri, S., Kelly-Hayes, M., Kase, C.S. and Wolf, P.A. (2009) Stroke in women: Gender differences in stroke incidence and post-stroke disability in the Framingham Heart Study. Stroke, 40, 10321037. doi:10.1161/strokeaha.108.542894

[13] Wyller, T.B. (1999) Stroke and gender. Journal of Gender-Specific Medicine, 2, 41-45.

[14] Modena, M.G., Bonetti, L., Coppi, F., Bursi, F. and Rossi, R. (2002) Prognostic role of reversible endothelial dysfunction in hypertensive postmenopausal women. Journal of the American College of Cardiology, 40, 505-510. doi:10.1016/S0735-1097(02)01976-9

[15] Nguyen, D.H., Paule, P., Pham, N.S., Michel, R., Vu Dien, B. and Fourcade, L. (2007) Etude des facteurs de risque cardiovasculaire associés à l'athérosclérose de l'aorte thoracique dépistée par échocardiographie transœsophagienne au Viêt-Nam. Médecine Tropicale, 67, 573-578.

[16] Roof, R.L. and Hall, E.D. (2000) Gender differences in acute CNS trauma and stroke: Neuroprotective effects of estrogen and progesterone. Journal of Neurotrauma, 17, 367-388. doi:10.1089/neu.2000.17.367

[17] Sibon, I., Lasalle-Lagadec, S., Renou, P. and Swendsen, J. (2012) Evolution of depression symptoms following stroke: A prospective study using computerized ambulatory monitoring. Cerebrovascular Diseases, 33, 280-285. doi:10.1159/000334663

[18] Carota, A. and Paoluci, S. (2007) Depression after stroke. In: Godefroy, O. and Bogousslavsky, J., Eds., The Behavioral and Cognitive Neurology of Stroke, Cambridge University Press, Cambridge, 548-570. doi:10.1017/CBO9780511544880.030

[19] Camus, V. and Schmitt, L. (2000) Manifestations psychiatriques des affections cérébrovasculaires: Approche clinique et thérapeutique. Encyclopédie MédicoChirurgicale Psychiatrie.
[20] Herrmann, N., Black, S.E., Lawrence, J., Szekely, C. and Szalai, J.P. (1998) The sunnybrook stroke study: A prospective study of depressive symptoms and functional outcome. Stroke, 29, 618-624. doi:10.1161/01.STR.29.3.618

[21] Paolucci, S., Antonucci, G., Pratesi, L., Traballesi, M., Grasso, M.G. and Lubich, S. (1999) Poststroke depression and its role in rehabilitation of inpatients. Archives of Physical Medicine and Rehabilitation, 80, 985-990. doi:10.1016/S0003-9993(99)90048-5

[22] Eriksson, M., Asplund, K., Glader, E.L., Norrving, B., Stegmayr, B., Terént, A., Asberg, K.H. and Wester, P.O. (2004) Riks-stroke collaboration self-reported depression and use of antidepressant after stroke: A national survey. Stroke, 35, 936-941.

doi:10.1161/01.STR.0000121643.86762.9a

[23] Oladiji, J.O., Akinbo, S.R.A., Aina, O.F. and Aiyejunsule, C.B. (2009) Risk factor of post-stroke depression among stroke survivors in Lagos, Nigeria. African Journal of Psychiatry, 12, 47-51.

[24] Carod-Art, F.J., Coral, F.L., Trizotto, D.F. and Moreira, C.M. (2009) Poststroke depression: Prevalence and determinants in Brazilian stroke depression. Cerebrovascular Diseases, 28, 157-165. doi:10.1159/000226114

[25] Chatterjee, K., Fall, S. and Barer, D. (2010) Mood after stroke: A case control study of biochemical, neuro-imaging and socio-economic risk factors for major depression in stroke survivors. BMC Neurology, 10, 125. doi:10.1186/1471-2377-10-125

[26] Lincoln, N.B. and Flannaghan, T. (2003) Cognitive behavioral psychotherapy for depression following stroke: A randomized controlled trial. Stroke, 34, 111-115. doi:10.1161/01.STR.0000044167.44670.55

[27] Kotila, M., Numminen, H., Waltimo, O. and Kaste, M. (1998) Depression after stroke results of the Finnstroke study. Stroke, 29, 368-372. doi:10.1161/01.STR.29.2.368

[28] Owolabi, M.O. (2008) Determinants of health-related quality of life in Nigerian stroke survivors. Transactions of the Royal Society of Tropical Medicine and Hygiene, 102, 1219-1225. doi:10.1016/j.trstmh.2008.05.003

[29] Cossi, M.J., Gobron, C., Preux, P.M., Niama, D., Chabriat, H. and Houinato, D. (2012) Stroke: Prevalence and disability in Cotonou, Benin. Cerebrovascular Diseases, 33, 166-172. doi:10.1159/000334195.

[30] Glamcevski II, M.T., McArthr, L.C., Chong, H.T. and Tan, C.T. (2002) Factors associated with post-stroke depression, a malaysian study. Neurological Journal of South East Asia, 7, 9-12.

[31] Paradiso, S. and Robinson, R.G. (1998) Gender differrences in poststroke depression. Journal of Neuropsychiatry, 10, 41-47.

[32] Ollat, H. (2000) Dépressions vasculaires. Neuropsychiatrie: Tendances et Débats, 10, 19-22.

[33] Ministère de l'enseignement primaire et secondaire (2005) Plan d'action nationale de l'éducation pour tous, Kinshasa.

http://planipolis.iiep.unesco.org/upload/Congo\%20DR/C ongo $\% 20 \mathrm{DR} \% 20 \mathrm{PAN}-\mathrm{EPT} \% 20$ Projet.pdf

[34] Salter, K., Bhogal, S., Teasell, R., Foley, N. and Spee- 
chley, M. (2011) Post-stroke depression. In: Teasell, R., Foley, N. and Salter, K. Eds., Evidence-Based Review of Stroke Rehabilitation, Module 18, 14th Edition, Heart and Stroke Foundation of Ontario, London.

http://www.ebrsr.com/reviews details.php?Post-Stroke-D epression-8

[35] Sienkiewicz-Jarosz, H., Milewska, D., Bochyńska, A., Chełmniak, A., Dworek, N., Kasprzyk, K., Gałecka, K., Szczepańska-Szarej, A., Chwojnicki, K., Zyluk, B., Słowik, A. and Ryglewicz, D. (2010) Predictors of depressive symptoms in patients with stroke-A three-month follow-up. Neurologia i Neurochirurgia Polska, 44, 1320.

[36] Fiske, A., Wetherell, J.L. and Gatz, M. (2009) Depression in older adults, Annual Review of Clinical Psychology, 5, 363-389.

[37] Jopson, N.M. and Moss-Morris, R. (2003) The role of illness severity and illness representations in adjusting to multi-plesclerosis. Journal of Psychosomatic Research, 54, 503-511. doi:10.1016/S0022-3999(02)00455-5

[38] Central Intelligence Agency (2013) Democratic Republic of Congo.

https://www.cia.gov/library/publications/the-world-factbo ok/geos/cg.html

[39] Giaquinto, S., Spiridigliozzi, C. and Caracciolo, B. (2007) Can faith protect from emotional distress after stroke? Stroke, 38, 993-997. doi:10.1161/01.STR.0000257996.26950.59

[40] Sloan, R.P., Bagiella, E. and Powell, T. (1999) Religion, spirituality, and medicine. Lancet, 353, 664-667. doi:10.1016/S0140-6736(98)07376-0

[41] Joshi, S., Kumari, S. and Jain, M. (2008) Religious belief and its relation to psychological well-being. Journal of the Indian Academy of Applied Psychology, 34, 345-354.

[42] Giaquinto, S., Sarno, S., Dall'Armi, V. and Spiridigliozzi, C. (2010) Religious and spiritual beliefs in stroke rehabilitation, Clinical and Experimental Hypertension, 32, 329-334. doi:10.3109/10641960903443566

[43] Brunon, A.R., Benseñor, I.M. and De Toledo Ferraz Alves, T.C. (2011) Therapeutic interventions for vascular depression: A systematic review. Revista Brasileira de Psiquiatria, 33, 400-409. doi:10.1590/S1516-44462011000400015
[44] Burvill, P., Johnson, G., Jamrozik, K., Anderson, C. and Stew-art-Wynne, E. (1997) Risk factors for post-stroke depresssion. International Journal of Geriatric Psychiatry, 12, 219-226.

doi:10.1002/(SICI)1099-1166(199702)12:2<219::AID-G PS581>3.0.CO;2-E

[45] Kuklina, E.V., Tong, X., George, M.G. and Bansil, P. (2012) Epidemiology and prevention of stroke: A worldwide perspective. Expert Review of Neurotherapeutics, 12, 199-208. doi:10.1586/ern.11.99

[46] Pariel-Madjlessi, S., Pouillon, M., Robcis, I., Sebban, C., Frémont, P. and Belmin, J. (2005) La dépression: Une complication méconnue de l'accident vasculaire cérébral chez les sujets âgés. Psychol Neuropsychiatr Vieil, 3, 716.

[47] Nidhinandana, S., Sithinamsuwan, P., Chinvarun, Y., Wongmek, W., Supakasem, S. and Suwantamee, J. (2010) Prevalence of poststroke depression in Thai stroke survivors studied in Phramongkutklao Hospital. Journal of the Medical Association of Thailand, 93, S60-S64.

[48] Santos, M., Kövari, E., Gold, G., Bozikas, V.P., Hof, P.R., Bouras, C. and Giannakopoulos, P. (2009) The neuro-anatomical model of post-stroke depression: Towards a change of focus? Journal of the Neurological Sciences, 283, 158-162. doi:10.1016/j.jns.2009.02.334

[49] Morris, P.L., Robinson, R.G., Raphael, B. and Bishop, D. (1991) The relationship between the perception of social support and post-stroke depression in hospitalized patients. Psychiatry, 54, 306-316.

[50] Hilari, K., Northcott, S., Roy, P., Marshall, J., Wiggins, R.D., Chataway, J. and Ames, D. (2010) Psychological distress after stroke and aphasia: The first six months. Clinical Rehabilitation, 24, 181-190. doi:10.1177/0269215509346090

[51] Boden-Albala, B., Litwak, E., Elkind, M.S., Rundek, T. and Sacco, R.L. (2005) Social isolation and outcomes post stroke. Neurology, 64, 1888-1892. doi:10.1212/01.WNL.0000163510.79351.AF

[52] Farner, L., Wagle, J., Engedal, K., Flekkøy, K.M., Wyller, T.B. and Fure, B. (2010) Depressive symptoms in stroke patients: A 13 month follow-up study of patients referred to a rehabilitation unit. Journal of Affective Disorders, 127, 211-218. doi:10.1016/j.jad.2010.05.025 